\title{
Application of a Single-phase Five-level Converter for High- voltage and Partial Discharge Tests on Potential Transformers
}

\author{
Noppadol Yomkaew, ${ }^{1}$ Peerawut Yutthagowith, ${ }^{1 *}$ and Tongpian Prombud ${ }^{2}$ \\ ${ }^{1}$ School of Engineering, King Mongkut's Institute of Technology Ladkrabang, \\ 1 Soi Chalongkrung 1, Ladkrabang, Bangkok, 10520, Thailand \\ ${ }^{2}$ Faculty of Engineering, Rajamangala University of Technology Krungthep, \\ 2 Nanglinchee Road, Thung Maha Mek, Sathon, Bangkok 10120, Thailand
}

(Received January 30, 2021; accepted June 14, 2021)

Keywords: partial discharge test, background noise, potential transformers, single-phase five-level converter, sinusoidal pulse width modulation

This paper presents an application of a single-phase five-level converter as a low-voltage source fed to a high-voltage (HV) transformer for HV and partial discharge (PD) tests on potential transformers with a voltage rating of $33 \mathrm{kV}$. The converter was constructed with two H-bridge sets of insulated gate bipolar transistor (IGBT) switches, and the sinusoidal pulse width modulation (SPWM) technique was utilized to control the converter. Also, an additional filter was implemented in the testing system to mitigate the background noise level in the HV testing system, and the suitable modulation index and carrier frequency were analyzed. To evaluate the performance of the developed testing system, the difference in the voltage, the total harmonic distortion, and the background noise in the PD tests were examined by simulations and experiments without and with a test object. From the simulation and experimental results, it was found that (i) the difference in the voltage is below $1 \%$, (ii) the total harmonic distortion is below $1 \%$, and (iii) the background noise is below $2 \mathrm{pC}$. The performances of the proposed converter in terms of output voltage distortion and switching interference are superior to those of the conventional three-level converter. This makes the developed system very attractive for use in practical HV and PD tests.

\section{Introduction}

Partial discharge (PD) causes the deterioration of insulation material under a high electrical field stress condition. It is necessary to detect the PD in high-voltage (HV) equipment at an early stage before it leads to complete breakdown. Many sensors are used for the detection of PD, such as high-frequency current transducers, electromagnetic field sensors, and measuring impedances. According to the standard IEC 60270, a system composed of measuring impedances is acceptable for PD detection. In addition, a PD testing system requires the following standard testing conditions: the difference in the voltage, the total harmonic distortion $\left(T H D_{v}\right)$ of the testing voltage, and the background noise should be lower than $5 \%, 5 \%$, and $2.5 \mathrm{pC}$, respectively. *Corresponding author: e-mail: peerawut.yu@kmitl.ac.th https://doi.org/10.18494/SAM.2021.3311 
Currently, the PD test is a routine test of the potential transformer production line. A PD level below the standard recommended value is sufficient to confirm the quality of the insulation. This allows users to expect potential transformers to have an appropriate lifetime when they are installed in electrical power distribution and transmission systems. The PD test must be performed according to national and international standards such as IEC $60270^{(1)}$ and IEC 60060-1. ${ }^{(2)}$ For PD tests, the procedure by which the testing voltage is applied to the potential transformer is illustrated in Fig. $1^{(2-4)}$ Under the pre-stress condition, the applied voltage is raised to $80 \%$ of the withstand voltage $\left(U_{t}\right)$ for $60 \mathrm{~s}$. Then, the testing voltage is reduced to $1.2 U_{r}$ for $30 \mathrm{~s}$, where $U_{r}$ is the nominal rating voltage. If we apply the required $\mathrm{AC} \mathrm{HV}$ at the rating frequency to the potential transformer under test, the core saturation effect may occur. The saturation condition affects the $\mathrm{AC}$ voltage testing waveform, distorting it from a sinusoidal waveshape. The standard requires a testing voltage for which the difference in the voltage and $T H D_{v}$ are both less than $5 \%$, where the difference in the voltage is defined as the difference between the root mean square (rms) voltage and the peak voltage divided by $\sqrt{2}$. To avoid the saturation condition, it is necessary to increase the frequency of the power source voltage. ${ }^{(2-7)} \mathrm{A}$ suitable testing frequency for testing with a rating frequency of 50 or $60 \mathrm{~Hz}$ is about $200 \mathrm{~Hz}$. Therefore, a motor-generator test set (where the generator is fed by a motor) is normally used to generate a voltage with a frequency of $200 \mathrm{~Hz}$ for the $\mathrm{HV}$ testing system, and the voltage waveform is purely sinusoidal with low harmonic distortion and low noise generation. However, the disadvantages of the generator are the high cost of both the equipment and its maintenance, and the large area required to set it up in the testing field.

Nowadays, power converter technology is constantly evolving and is widely applied to enhance both performance and reliability in many application fields. One of its applications related to this paper is the generation of the $\mathrm{HV}$ in the $\mathrm{HV}$ testing of $\mathrm{HV}$ equipment. A conventional power converter was implemented to coordinate with the filter used in PD tests and applied to test potential transformers. ${ }^{(8-12)}$ In this study, the performance of the testing voltage for a PD testing system was confirmed in terms of $T H D_{v}$ of the output voltage and the background noise. Under the pre-stress condition of about $40 \mathrm{kV}$, the resultant $T H D_{v}$ was $0.8 \%$ and the background noise was around $2.5 \mathrm{pC}$. Under the PD recording condition of about $30 \mathrm{kV}$, $T H D_{v}$ was $0.8 \%$ and the background noise was around $1.9 \mathrm{pC}$. In these cases, the performance of

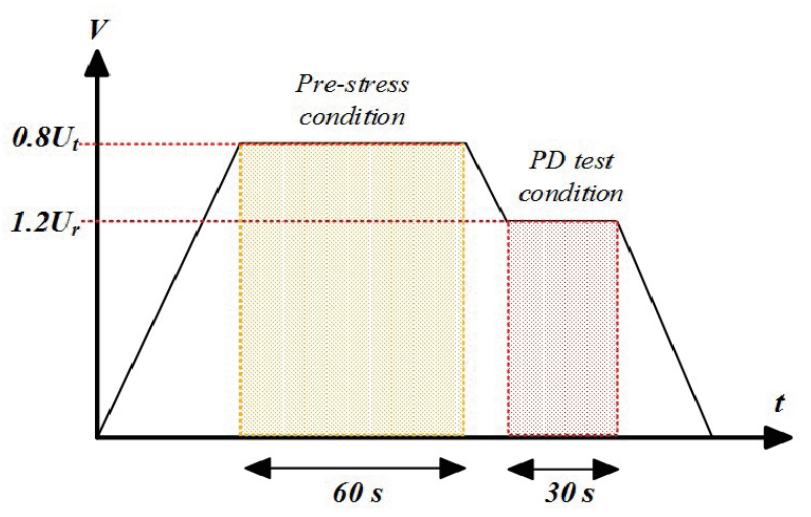

Fig. 1. (Color online) PD test procedure for a potential transformer. 
the system is acceptable for tests with a potential transformer of $24 \mathrm{kV}$ rating. It was observed that the background noise increased with the applied voltage. If this system is applied to test at a higher voltage, the background noise will be higher than $2.5 \mathrm{pC}$, which is not acceptable for testing potential transformers.

However, the potential transformers available in the distribution system of Thailand have various rating voltages, i.e., 12, 24, and $33 \mathrm{kV}$. With the system developed in Refs. 8-12, potential transformers with a rating voltage not higher than $24 \mathrm{kV}$ have been tested with the standard requirement. As mentioned above, the system cannot test potential transformers with a rating voltage of $33 \mathrm{kV}$. Therefore, the PD testing system developed in this study must support HV and PD tests of a potential transformer with a rating voltage of $33 \mathrm{kV}$. The developed system must satisfy the standard testing requirements in terms of the quality of the testing voltage (the difference between the voltage and $T H D_{v}$ ) and the background noise level. The testing voltage for the pre-stress condition of $80 \%$ of the withstanding voltage is $56 \mathrm{kV}$, and the testing voltage under the PD recording condition is $43.2 \mathrm{kV}$.

In this paper, a five-level converter is proposed to improve the performance of the testing system in terms of the output voltage distortion and interference level. At the same output voltage, the input DC voltage of the five-level converter is $50 \%$ of that of a conventional threelevel converter, so the background noise caused by the switching voltage is also reduced to around $50 \%$ of the conventional value. ${ }^{(12)}$ In addition, a filter circuit was implemented in the developed converter to reduce the background noise to an acceptable level meeting the standard requirement. ${ }^{(1)}$ The developed system was analyzed, designed, and tested to confirm its validity in tests with and without a potential transformer. It was found that throughout the testing voltage range, the difference between the voltage and that at a suitable switching frequency, $T H D_{v}$, and the background noise level were less than $2 \%, 2 \%$, and $2 \mathrm{pC}$, respectively. On the basis of these promising results, the developed system has been confirmed to be very attractive for use in practical HV and PD tests.

\section{Development of Proposed PD Testing System}

The PD testing system, as shown in Fig. 2, is composed of a voltage source, a low-pass filter, an HV testing transformer, and a PD detection system in accordance with IEC 60270. The PD

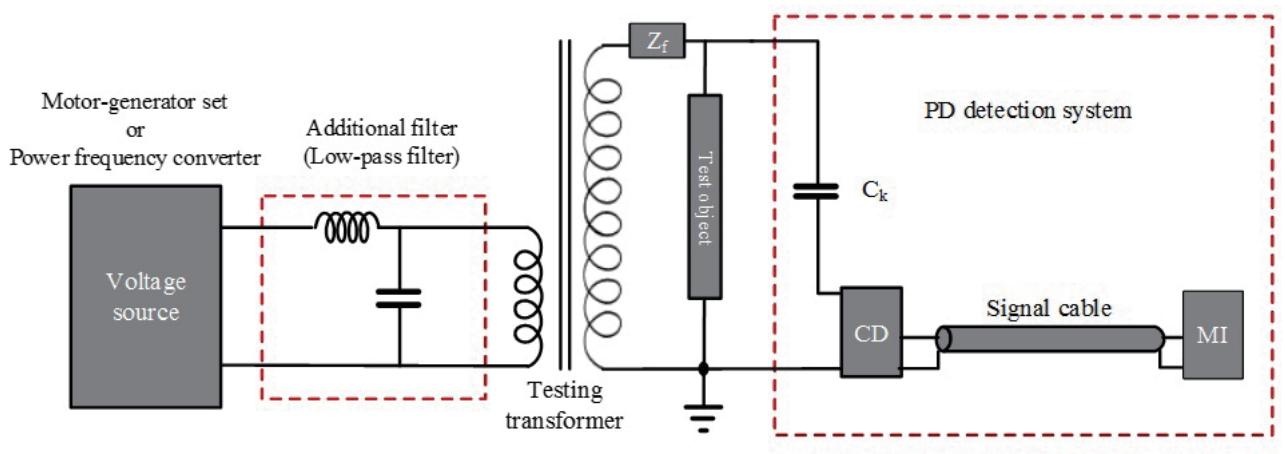

Fig. 2. (Color online) PD testing system. 
detection system is composed of a coupling capacitor $\left(\mathrm{C}_{\mathrm{k}}\right)$, a coupling device (CD) or a measuring impedance, a signal cable, and a measuring instrument (MI). The test object of this study is a potential transformer with a $33 \mathrm{kV}$ rating.

In the PD tests, the test environment must be controlled to meet the standard requirement. First, the testing voltage waveform should be close to purely sinusoidal, so $T H D_{v}$ should be controlled to below $5 \% . T H D_{v}$ is defined by

$$
T H D_{v}=\frac{1}{V_{1}} \sqrt{\sum_{n=2}^{50} V_{n}^{2}},
$$

where $V_{1}$ is the peak of the fundamental voltage and $V_{n}$ is the peak of the nth harmonic voltage. Second, the voltage difference of the testing voltage, defined as the difference between the RMS value of the testing voltage and the peak of the testing voltage divided by $\sqrt{2}$, should be controlled to lower than 5\%. The other control factor is the background noise of the testing system. In the case of high background noise, the PD result cannot be specified. To meet the standard, the background noise must be controlled to below $2.5 \mathrm{pC}$ for testing of the potential transformer.

In this paper, a five-level converter with an additional filter is proposed to meet the standard requirements ${ }^{(1,4,5)}$ in the PD test on a potential transformer. For better understanding, this section starts with an explanation of the effect of the converter switching voltage on a PD detection system, and the advantages of the five-level converter over a conventional three-level converter are presented. Finally, an appropriate additional filter for reducing the background noise level is presented in this section.

\subsection{Effects of converter switching voltage on PD detection system}

In a PD testing system, a CD or measuring impedance is connected to a coupling capacitor $\left(\mathrm{C}_{\mathrm{k}}\right)$. The measuring impedance circuit proposed in this study is shown in Fig. 3. As shown in Fig. 4, the transfer impedance of the measuring impedance is in the form of a band-pass filter with low and high cutoff frequencies of about 30 and $20 \mathrm{MHz}$, respectively.

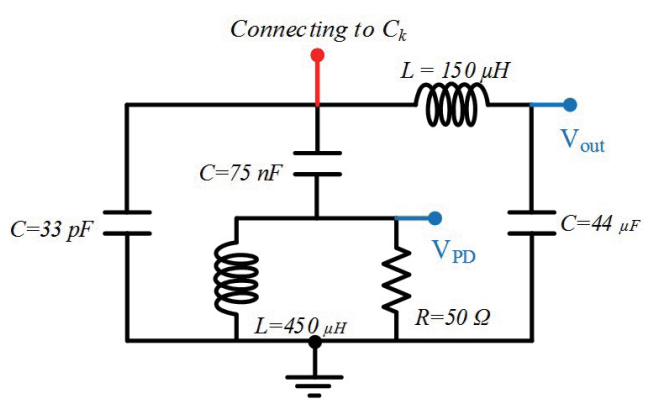

Fig. 3. (Color online) Measuring impedance circuit.

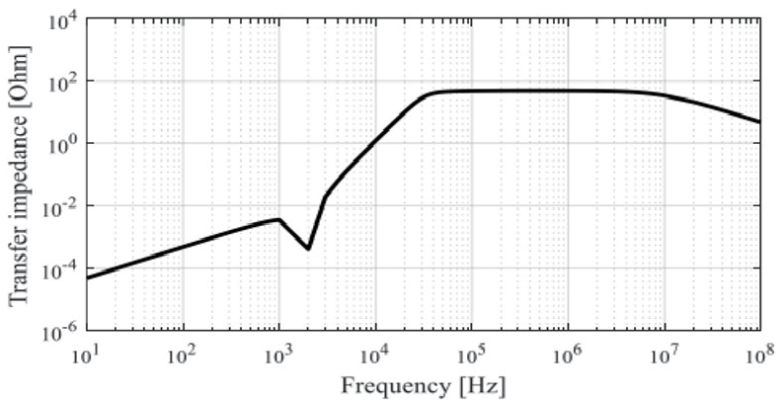

Fig. 4. Transfer impedance characteristic. 
In the analyses, the circuit parameters for the testing transformer are transferred to the HV side of the transformer with a specification rating of $460 \mathrm{~V} / 75 \mathrm{kV}, 40 \mathrm{kVA}$. The equivalent circuit of the system is shown in Fig. 5. The transfer function of the output voltage $\left(V_{\text {out }} / V_{\text {inv }}\right)$ can be determined as shown in Fig. 6. In the simulation using a circuit simulator (EMTP/ATP), a simulated PD pulse current with an electric charge of $2.5 \mathrm{pC}$ was injected into the testing system, and the peak voltage from the PD current was $5 \mathrm{mV}$ as shown in Fig. 7.

Under the simulation conditions of the single-phase five-level converter with the target output voltage (peak), $70 \mathrm{kVrms}$ (about $100 \mathrm{kV}_{\mathrm{p}}$ ), and $200 \mathrm{~Hz}$, the switching frequency of the controlled signal was varied from 1 to $20 \mathrm{kHz}$ and the modulation index was set to either 1.0 or 0.8 . From the results, there is no significant effect of the switching frequency or the modulation index on the output voltage waveform. In all the considered cases, the difference in the voltage and $T H D_{v}$ are both lower than 5\%, but the background noise level is very high (higher than $300 \mathrm{pC}$ ). In Figs. 8 and 9, the input voltage from the converter (transferred to the HV) and the voltage signal (the interference signal) from the PD port in the case of a switching frequency of $6.4 \mathrm{kHz}$ and a modulation index $\left(m_{a}\right)$ of 1.0 are presented, respectively. $T H D_{v}$ is $0.95 \%$. The background noise

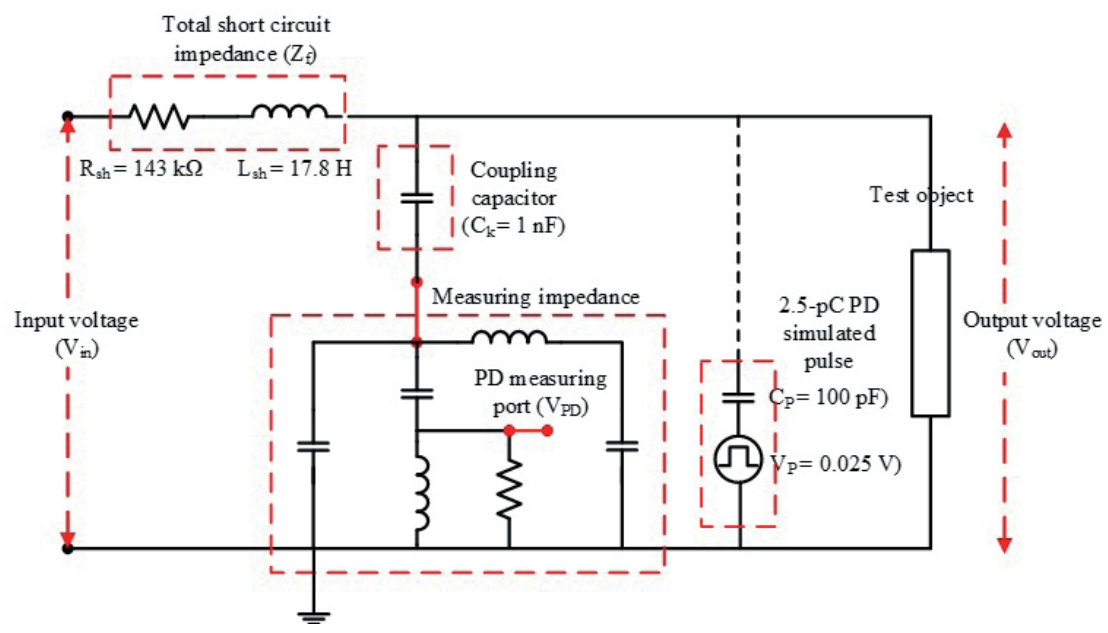

Fig. 5. (Color online) Equivalent circuit of the PD testing system.

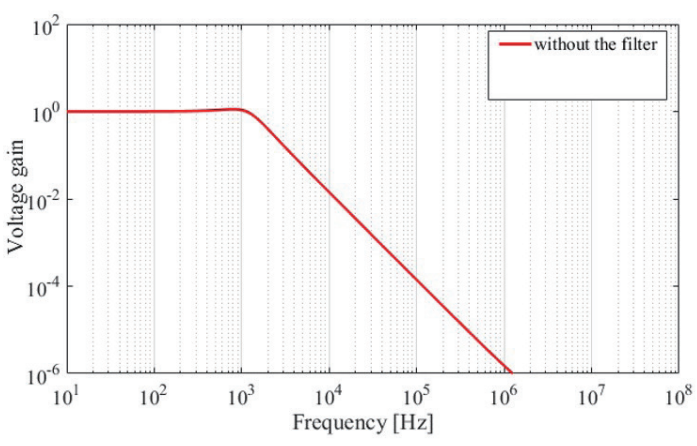

Fig. 6. (Color online) Frequency response of the testing system.

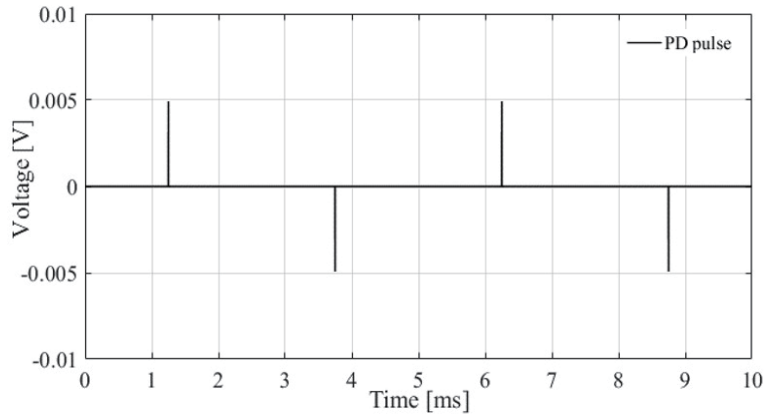

Fig. 7. Voltage at the PD port in the case of $2.5 \mathrm{pC}$ PD current injection to the testing system. 


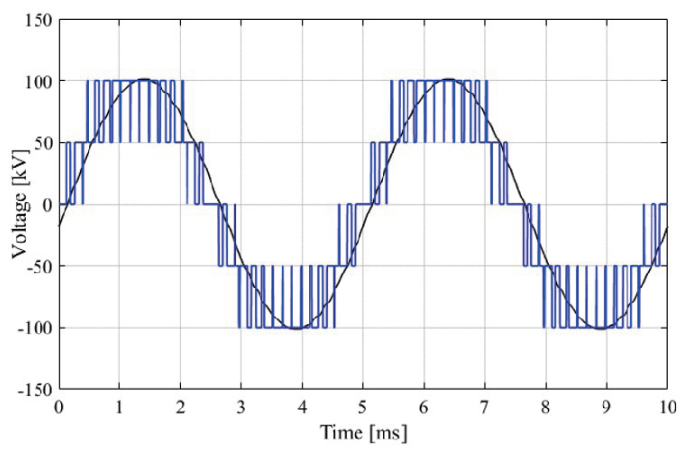

Fig. 8. (Color online) Input and output voltages $\left(V_{i n v}\right.$ and $\left.V_{\text {out }}\right)$ of the PD testing circuit.

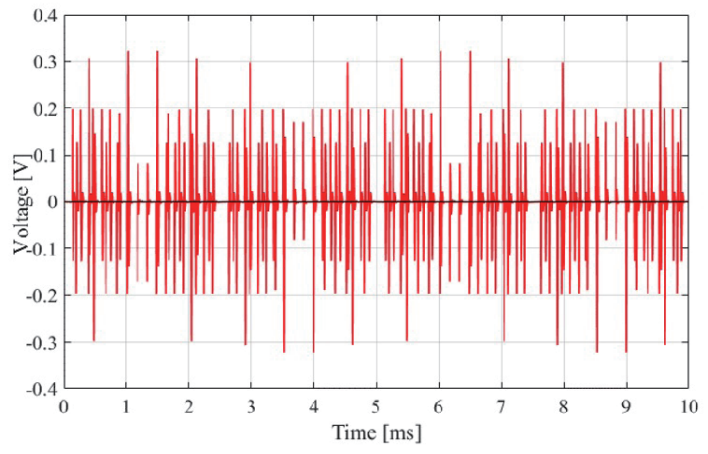

Fig. 9. (Color online) Voltage at the PD port $\left(\mathrm{V}_{\mathrm{PD}}\right)$.

level is $320 \mathrm{mV}$, which is much higher than the measured voltage $(5 \mathrm{mV})$ in the case of $2.5 \mathrm{pC}$ PD pulse injection. This noise level is equivalent to about $160 \mathrm{pC}$. Therefore, an additional filter must be connected to the system, as explained in Sect. 2.3.

\subsection{Advantages of the five-level converter}

In this paper, we propose a single-phase five-level converter fed to the $\mathrm{HV}$ testing transformer applied to the test object. The structure of the proposed converter, as shown in Fig. 10, is adapted from that of the conventional three-level converter. Two sets of cascaded H-bridges of the insulated gate bipolar transistor (IGBT) switches are constructed and connected in the series circuit. The $\mathrm{DC}$ input voltage $\left(\mathrm{V}_{\mathrm{DC}}\right)$ of the five-level converter is separated into two sources. Each $\mathrm{V}_{\mathrm{DC}}$ source value is half of the input voltage of the conventional converter. In this case, the peak output voltage of the developed system is the same as that of the conventional converter. ${ }^{(13-19)}$

The switching operation of the converter in each state is shown in Table 1, where 1 denotes switching on and 0 denotes switching off. Sinusoidal pulse width modulation (SPWM) is applied to control the switching operation of the single-phase five-level converter. The controlled signal and the output voltage of the converter are respectively shown in Figs. 11 and 12. Triangle waveforms with $m_{a}$ of 1.0 and 0.8 and carrier frequencies from 1.2 to $20 \mathrm{kHz}$ were used to examine their effects on the output voltage, $T H D_{v}$, and switching noise or the background noise of the testing system. The analysis focused on the generation of the output $\mathrm{HV}$ at the fundamental frequency of $200 \mathrm{~Hz}$, because this frequency is suitable for testing potential transformers with a rating frequency of 50 or $60 \mathrm{~Hz}$.

It is clear that the output voltage generated by the proposed single-phase five-level converter is closer to a sinusoidal waveform than that generated by the conventional three-level converter. ${ }^{(13-19)}$ Owing to the linear characteristic of the PD detection system, the switching noise associated with the background noise is dependent on the input DC voltage fed to the converter. At the same output voltage, the proposed system requires only half the input DC voltage of that of the conventional system. Therefore, the background noise of the proposed system is only half that of the conventional system. On the basis of this hypothesis, the five-level 


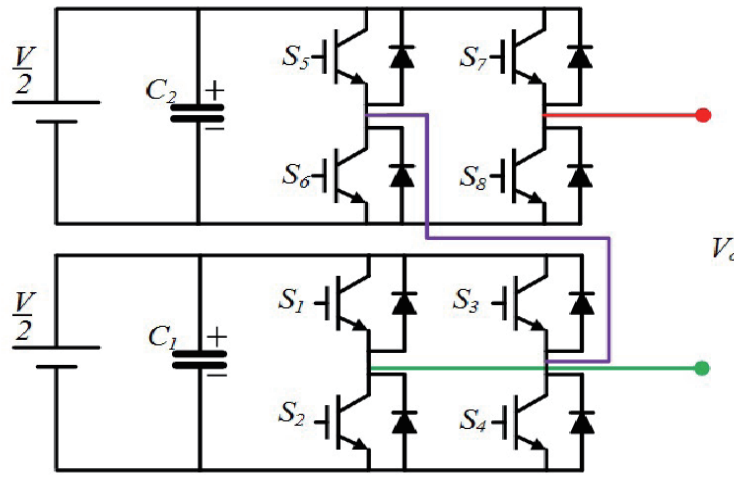

Fig. 10. (Color online) Single-phase five-level converter (CHB type).

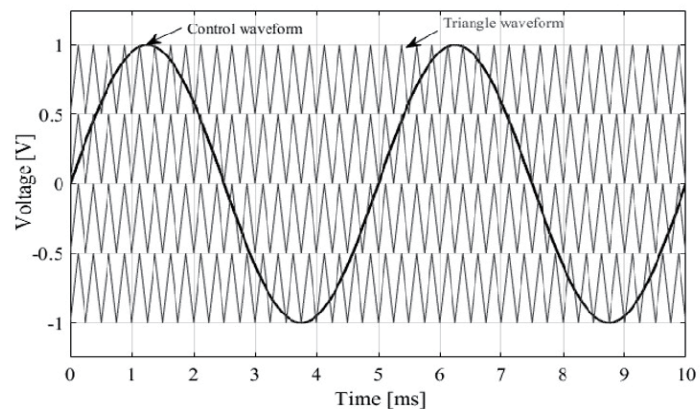

Fig. 11. SPWM for controlling the five-level converter.
Table 1

Switching operation of the single-phase five-level converter.

\begin{tabular}{lcccccccc}
\hline $\mathrm{V}_{\mathrm{o}}$ & $\mathrm{S} 1$ & $\mathrm{~S} 2$ & $\mathrm{~S} 3$ & $\mathrm{~S} 4$ & $\mathrm{~S} 5$ & $\mathrm{~S} 6$ & $\mathrm{~S} 7$ & $\mathrm{~S} 8$ \\
\hline $\mathrm{V}$ & 0 & 1 & 1 & 0 & 0 & 1 & 1 & 0 \\
$\mathrm{~V} / 2$ & 0 & 1 & 1 & 0 & 1 & 0 & 1 & 0 \\
0 & 1 & 0 & 1 & 0 & 1 & 0 & 1 & 0 \\
$-\mathrm{V} / 2$ & 1 & 0 & 0 & 1 & 1 & 0 & 1 & 0 \\
$-\mathrm{V}$ & 1 & 0 & 0 & 1 & 1 & 0 & 0 & 1 \\
\hline
\end{tabular}

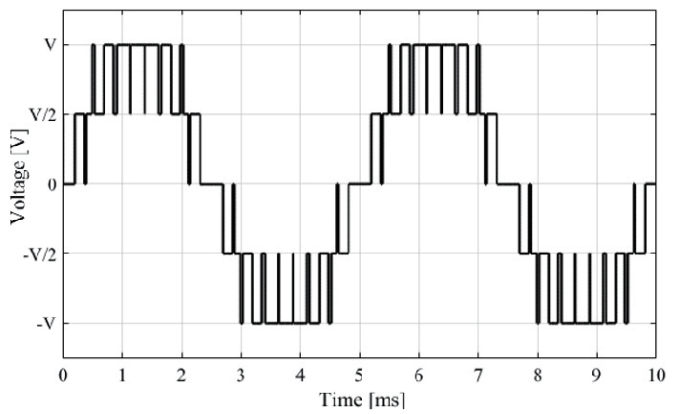

Fig. 12. Output voltage of single-phase five-level converter.

converter can improve the quality of the PD test for a potential transformer of $33 \mathrm{kV}$ rating. The analysis of the developed system will be presented in the next sections.

\subsection{Reduction of background noise using an additional filter}

As presented in the previous sections, an additional filter is required to attenuate the interference at the PD port. The filter is connected with the output of the converter and the lowvoltage side of the HV testing transformer as shown in Fig. 13. In the analyses, all circuit parameters are transferred to the HV side of the testing transformer.

The transfer function (the output voltage divided by the input voltage generated by the converter) was determined for filter capacitances $\left(C_{f}\right)$ of 0,1 , and $16 \mu \mathrm{F}$. The results for the different capacitances are shown in Fig. 14. Also, the effect of different filter capacitances $\left(C_{f}\right)$ $(0,1$, and $16 \mu \mathrm{F})$ on the transfer impedance (the voltage at the PD port divided by the input voltage generated by the converter) was investigated and the results are shown in Fig. 15.

It was found that the switching frequency does not affect the background noise level significantly. The input and output voltages and the interference at the PD port are respectively shown in Figs. 16 and 17 for an output voltage of $100 \mathrm{kV}_{\mathrm{p}}$, which is generated by the converter with a switching frequency of $6.4 \mathrm{kHz}$. $T H D_{v}$ of the output voltage is $0.90 \%$. The background noise is $1.2 \mathrm{mV}$, which is equivalent to $0.6 \mathrm{pC}$ (a $2.5 \mathrm{pC}$ PD current results in $5 \mathrm{mV}$ at the PD 


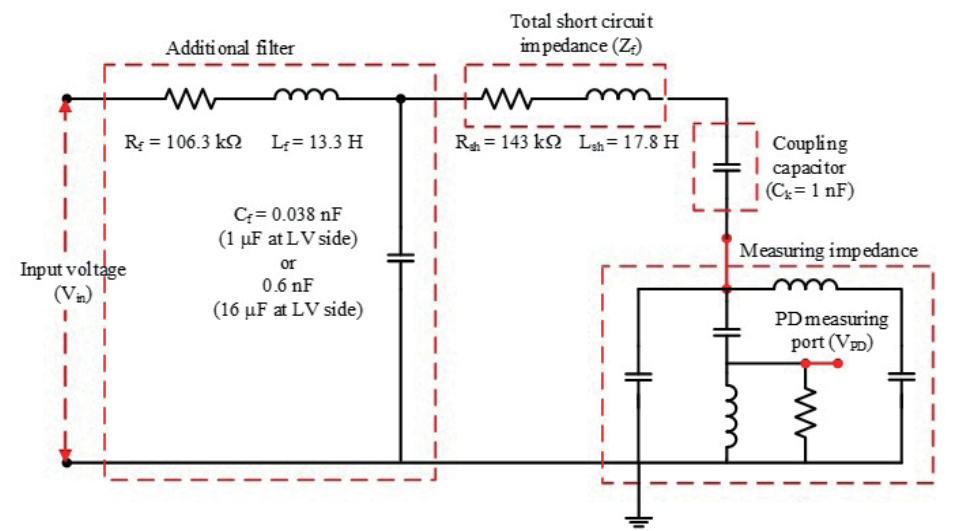

Fig. 13. (Color online) Equivalent circuit of the PD testing system with the filter circuit.

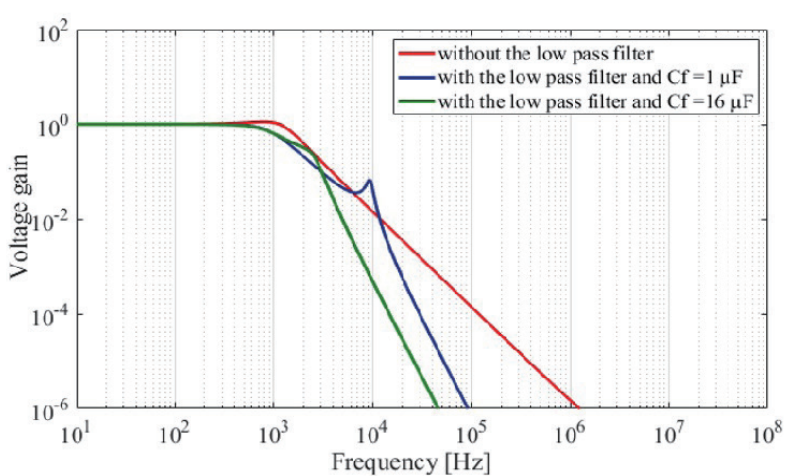

Fig. 14. (Color online) Transfer function (output voltage divided by input voltage) for $C_{f}=0,1$, and $16 \mu \mathrm{F}$.

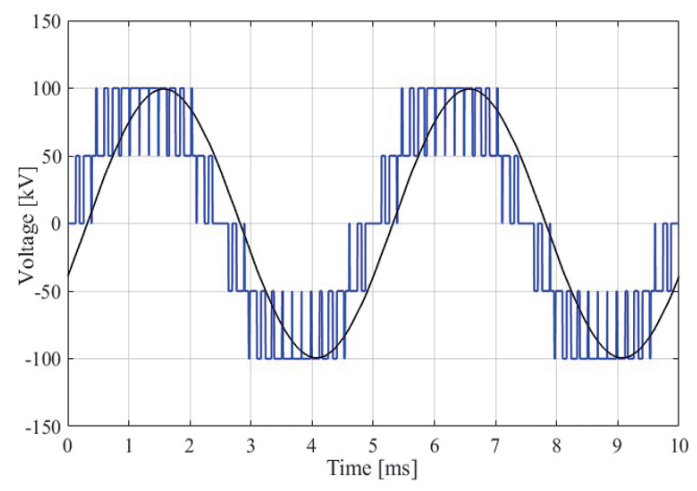

Fig. 16. (Color online) Output voltage in comparison with the input voltage from the converter transferred to the HV side.

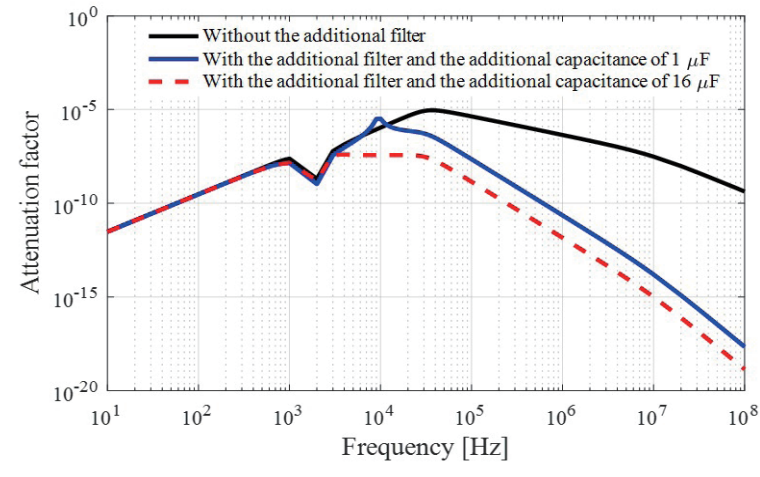

Fig. 15. (Color online) Transfer impedance (voltage at the PD port divided by input voltage) or the attenuation factor.

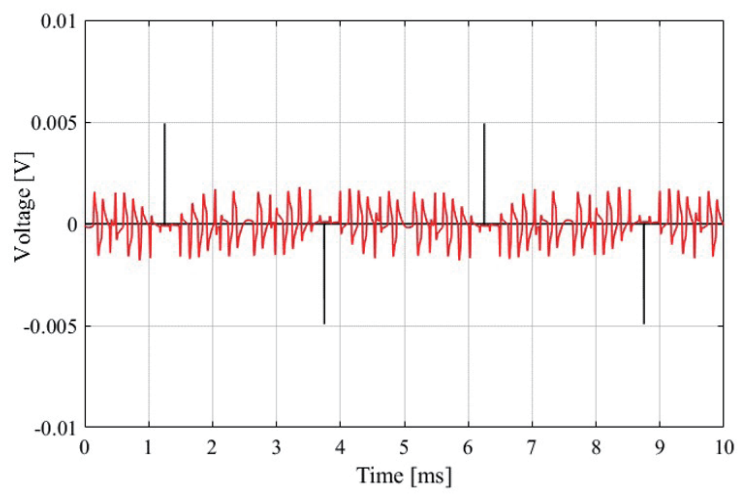

Fig. 17. (Color online) Background noise voltage in comparison with the voltage from $2.5 \mathrm{pC}$ PD current at the PD port with $C_{f}=16 \mu \mathrm{F}$.

port). It is clear that the additional filter can improve the quality of the PD testing significantly. To confirm the performance of the proposed system in PD tests, an experiment was set up with the potential transformer, which is presented in the next section. 


\section{Experimental Results}

The performances of the proposed system for PD tests were verified by two experiments, whose results were compared with those obtained with a conventional three-level converter. ${ }^{(12)}$ In the first experiment, various control conditions were applied to control the IGBTs of the developed converter, and the difference in the voltage, the $T H D_{v}$, and the background noise level were investigated. The fundamental frequency of the testing voltage was set to $200 \mathrm{~Hz}$, which is appropriate for testing a potential transformer without the core saturation effect. The switching frequency was varied from 1.2 to $20 \mathrm{kHz}$, the modulation index was either 1.0 or 0.8 , and the conditions giving the best performance were explored. We assumed that the test object does not affect the performance of the testing system because of the low load of the potential transformer. Therefore, the test object was not connected to the system. In the second experiment, a PD test was performed on a potential transformer. The experimental setup of the PD test is shown in Fig. 18. Similarly to in the equivalent testing circuit shown in Fig. 2, the converter was connected to the low-voltage winding of the HV transformer through the additional filter. Then, the HV side of the transformer was connected to the conventional PD measurement system and the test object. The specifications of the testing equipment are as follows.

- $\mathrm{HV}$ transformer rating $460 \mathrm{~V} / 75 \mathrm{kV}$, power $40 \mathrm{kVA}$.

- Omicron MPD600 conventional PD measurement system. ${ }^{(20)}$

- Potential transformer with rating voltage of $33 \mathrm{kV}$ used as test object (pre-stress and PD testing voltages for potential transformer of about 56 and $43.2 \mathrm{kV}$, respectively).

- Control signal generated by STM32F407 microcontroller.

In the first experiment, no test object was connected to the testing system. Considering the proposed system, the voltage level is given relative to the PD testing voltage as shown in Fig. 2. The testing voltage was increased to $56 \mathrm{kV}$ (pre-stress voltage), then the testing voltage was decreased to $43.2 \mathrm{kV}$ (voltage for recording the PD value). The difference in the voltage, $T H D_{v}$,

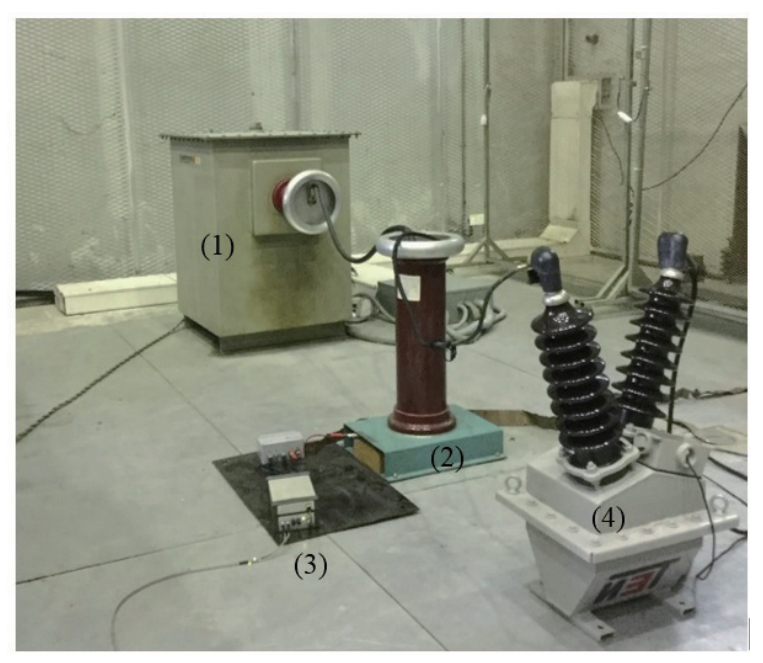

Fig. 18. (Color online) Experimental setup of the PD test. (1) HV testing transformer, (2) coupling capacitor, (3) CD for PD detection, and (4) test object. 
and background noise level were recorded. It was found that the difference in the voltage in all cases was lower than $1.0 \% . T H D_{v}$ and the background noise level under the pre-stress condition are shown in Fig. 19. Also, the results obtained at the voltage for recording the PD are shown in Fig. 20. Under the best conditions of the proposed system, the switching frequency and modulation index are $3.2 \mathrm{kHz}$ and 1.0 , respectively. The proposed system provides $T H D_{v}$ of $0.65 \%$ and a background noise level of $1.39 \mathrm{pC}$ at an output voltage of $43.63 \mathrm{kV}$. For the conventional system under the best conditions (switching frequency of $3.2 \mathrm{kHz}$, modulation index of 1.0, and output voltage of $40 \mathrm{kV}), T H D_{v}$ and the background noise level are $0.7 \%$ and $2.3 \mathrm{pC}$, respectively. ${ }^{(12)}$ By comparing the results obtained from the proposed and conventional systems, it has been confirmed that the proposed system is superior to the conventional one. For the cases considered, the output voltage waveforms under the PD recording condition and the background noise levels of the developed system with a switching carrier frequency of $3.2 \mathrm{kHz}$ and $m_{a}$ of 0.8 and 1.0 are shown in Fig. 21. Also, the results under the pre-stress condition and $m_{a}$ of 1.0 are shown in Fig. 22.

According to the results of the first experiment, to minimize $T H D_{v}$ and the background noise level, the most appropriate modulation index and switching frequency are 1.0 and $3.2 \mathrm{kHz}$, respectively.

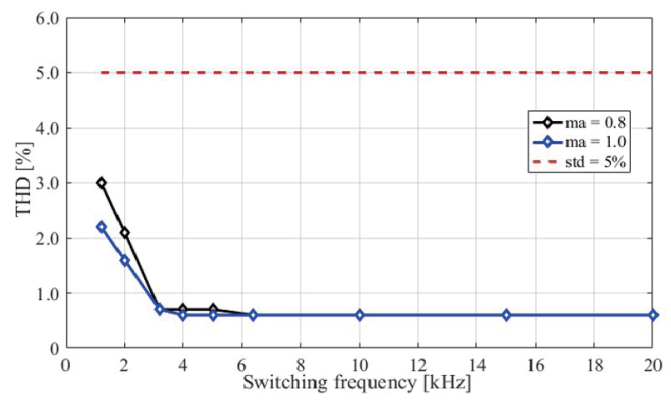

(a)

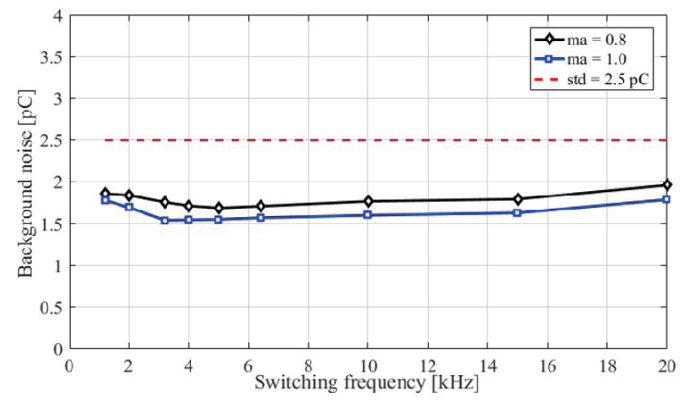

(b)

Fig. 19. (Color online) (a) $T H D_{v}$ and (b) background noise under the pre-stress condition with the switching frequency varied from 1.2 to $20 \mathrm{kHz}$ and $m_{a}$ of 0.8 and 1.0 .

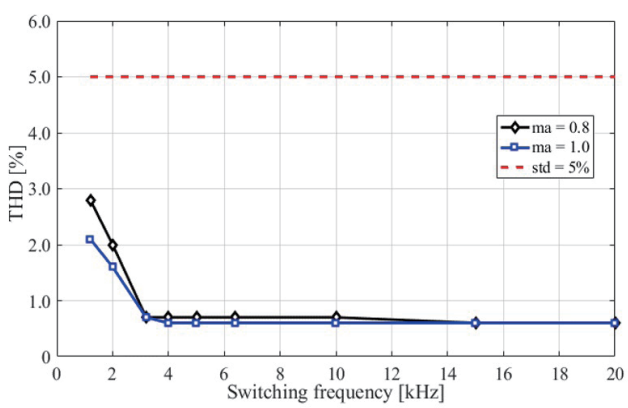

(a)

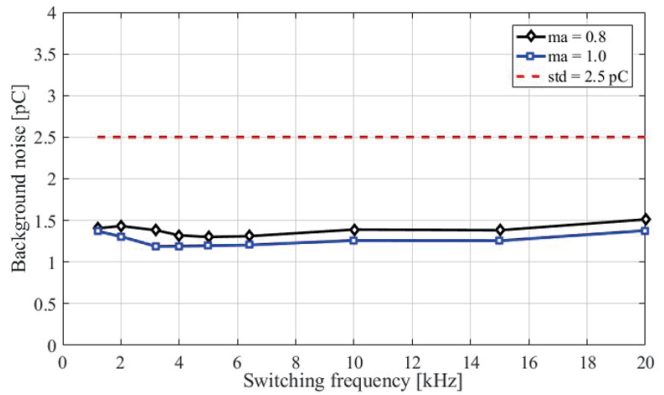

(b)

Fig. 20. (Color online) (a) $T H D_{v}$ and (b) background noise under the recording PD condition with the switching frequency varied from 1.2 to $20 \mathrm{kHz}$ and $m_{a}$ of 0.8 and 1.0 . 


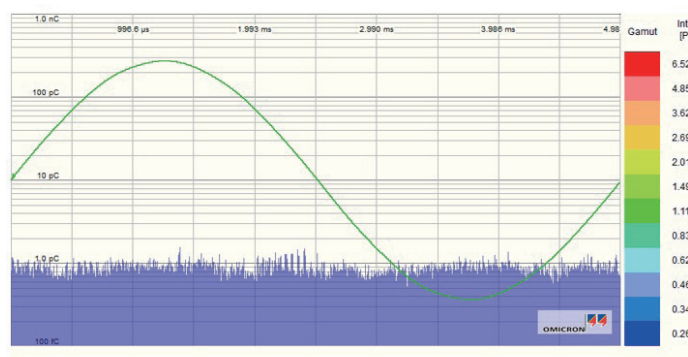

(a)

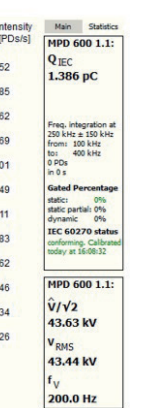

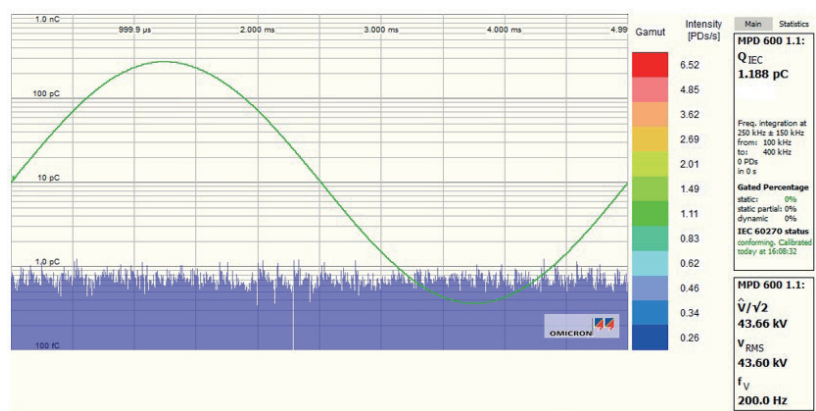

(b)

Fig. 21. (Color online) Output voltage waveforms and background noise levels under the recording PD condition with a switching frequency of $3.2 \mathrm{kHz}$ and $m_{a}$ of (a) 0.8 and (b) 1.0 .

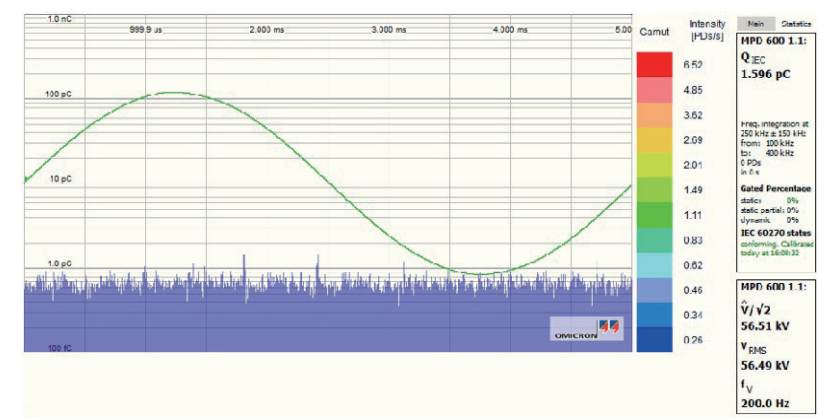

Fig. 22. (Color online) Output voltage waveform and the background noise level under the pre-stress condition $\left(m_{a}=1.0\right)$.

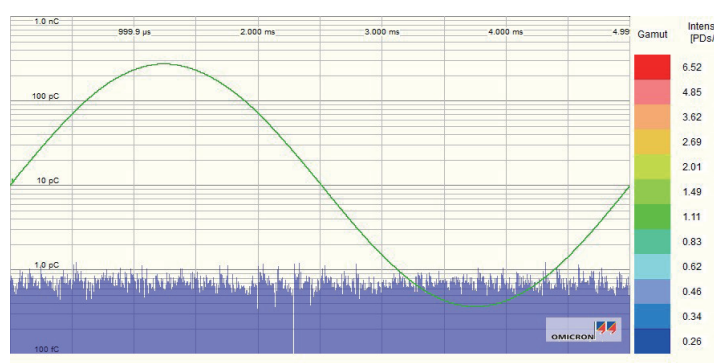

(a)

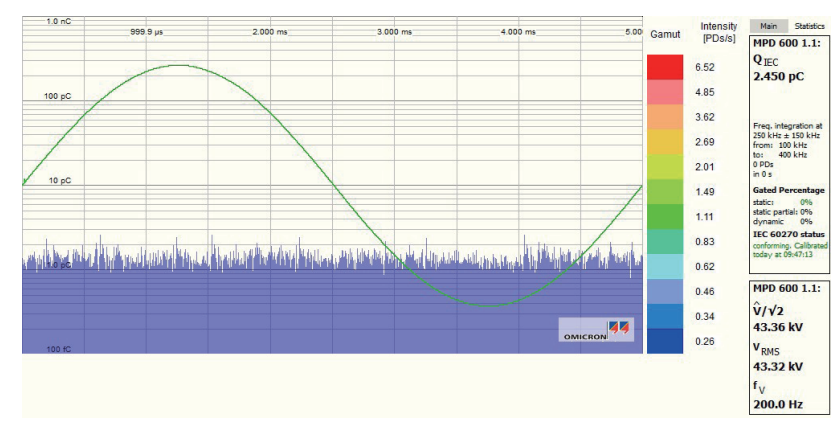

(b)

Fig. 23. (Color online) Output voltage waveforms under the recording PD condition in the PD test of the potential transformer. (a) Proposed system and (b) conventional system.

In the second experiment, the developed system was used for the PD test on the potential transformer. A switching frequency of $3.2 \mathrm{kHz}$ and a modulation index of 1.0 were set for the controlled signal of the converter. The voltage waveform and the background noise under the PD recording condition are shown in Fig. 23(a). To compare the performance of the proposed system, the same experiment was carried out with the conventional three-level converter with the same switching frequency and modulation index. The results are shown in Fig. 23(b). It can 
be seen that the output voltage waveforms at about the same voltage are almost purely sinusoidal, but the background noise of the proposed system is only half that of the conventional converter, in good agreement with the simulation results presented in Sect. 2.

\section{Conclusions}

We developed a PD testing system based on a single-phase five-level converter for implementation in $\mathrm{HV}$ and $\mathrm{PD}$ tests on potential transformers with a $33 \mathrm{kV}$ rating. The performances of the developed system in terms of $T H D_{v}$ and the background noise were investigated by considering the converter control signal with the switching carrier frequency varied from 1.2 to $20 \mathrm{kHz}$ and a modulation index of ether 1.0 or 0.8 . The most appropriate conditions for the control signal of the converter were investigated experimentally, and a modulation index of 1.0 and a switching carrier frequency of $3.2 \mathrm{kHz}$ were found to be the best conditions. Under these conditions, the difference in the voltage was lower than $1 \%, T H D_{v}$ was lower than $1 \%$, and the background noise was lower than $1.5 \mathrm{pC}$. Finally, the proposed system was applied in actual HV and PD tests on a potential transformer with a $33 \mathrm{kV}$ rating. It was thus confirmed that the developed system is an attractive choice for HV and PD tests of potential transformers because the output voltage is very close to a purely sinusoidal function and the background noise level is low. However, the limitations and weak points of the proposed system are as follows: (1) eight switches are required for two H-bridge switches, twice the number required in the conventional three-level converter, (2) the system controlling the signal in the proposed system is more complicated than that in the conventional system, and (3) an additional filter is still required to reduce the background noise level.

\section{Acknowledgments}

The authors would like to give special acknowledgment to the School of Engineering, King Mongkut's Institute of Technology Ladkrabang for providing the facility in this research work. This project was funded by the National Research Council of Thailand.

\section{References}

1 High-Voltage Test Techniques: Partial Discharge Measurement, IEC Standard 60270 (2000).

2 High-Voltage Test Techniques: Part 1 General definitions and test requirements: International Standard IEC 60060-1, 3rd ed. (Geneva, Switzerland, 2010).

3 IEEE STD98158 4-2013. IEEE Standard for High-Voltage Testing Techniques.

4 Instrument Transformer-Part 1: General requirements, IEC Standard 61869-1 (2007).

5 Instrument Transformer-Part 3: Additional requirements for inductive voltage transformers, IEC Standard 61869-3 (2011).

6 W. Hauschild and E. Lemke: High-Voltage Test and Measuring Techniques (Springer, Heidelberg, 2014).

7 A. Thiedel and F. Martin: High Volt Prüftechnik Dresden GmbH, Power Frequency Inverters for High Voltage Tests, HighVolt Colloquium (2007).

8 B. Leelachariyakul, P. Yutthagowith, and S. Potivejkul: PD Detection Test of a Voltage Transformer Using a Variable Frequency Converter (ISET, 2015).

9 T. Prombud, P. Kitcharoen, and P. Yutthagowith: Proc. 2017 11th Int. Symp. EMC and Transients in Infrastructures and International Student Session (ISET/ISS, 2017) 31-34. 
10 T. Prombud, P. Kitcharoen, and P. Yutthagowith: Proc. 2018 Australasian Universities Power Engineering Conf. (AUPEC, 2018) 351-355.

11 T. Prombud, P. Kitcharoen, and P. Yutthagowith: Proc. 2018 IEEE Int. Conf. Industrial Technology (ICIT, 2018) $1685-1689$.

12 T. Prombud and P. Yutthagowith: Sens. Mater. 32 (2020) 573. https://doi.org/10.18494/SAM.2020.2531

13 D. G. Holmes and T. A. Lipo: Pulse Width Modulation for Power Converters, in Principles and Practice (John Wiley \& Sons, Inc., Jersey, 2003).

14 M. H. Rashid: Power Electronics Handbook (Butterworth-Heinemann, Massachusetts, 2011) 3rd ed.

15 T. L. Skvarenina: The Power Electronics Handbook (Crc press, New York, 2002).

16 A. Yadav, S. N. Singh, and S. P. Das: Proc. 2017 4th IEEE Uttar Pradesh Section Int. Conf. Electrical, Computer and Electronics (UPCON, 2017) 280-288.

17 P. Kitcharoen, P. Yutthagowith, A. Kunakorn, and W. Limcharoen: Proc. 2017 14th Int. Conf. Electrical Engineering/Electronics, Computer, Telecommunications and Information Technology. (ECTI-CON, 2017) 826-829.

18 N. Yomkaew, N. Marukatat, and P. Yutthagowith: Proc. 2018 Australasian Universities Power Engineering Conf. (AUPEC, 2018) 335-338.

19 N. Yomkaew and P. Yutthagowith: Proc. 2018 12th Int. Symp. EMC and Transients in Infrastructures and International Student Session. (ISET/ISS, 2018) 11-14.

20 User Manual for the Device MPD600: https://www.omicronenergy.com (accessed January 2019).

\section{About the Authors}

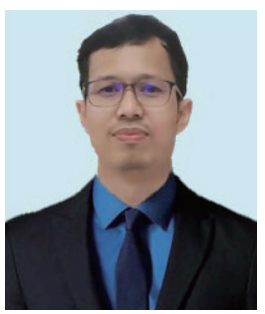

Noppadol Yomkaew received his B.Eng. and M.Eng. degrees from King Mongkut's Institute of Technology Ladkrabang (KMITL), Thailand, in 2005 and 2011, respectively. Since 2005, he has been an electrical engineer of Siam Compressor Industry, Mitsubishi Electric group. He is Ph.D. student in the Department of Electrical Engineering at KMITL. His research interests are in high-voltage engineering applications and sensors.

(63601019@kmitl.ac.th)

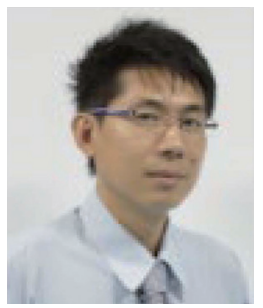

Peerawut Yutthagowith received his B.Eng. and M.Eng. degrees from Chulalongkorn University, Thailand, in 1998 and 2001, respectively, and his Ph.D. degree from Doshisha University, Japan, in 2010. Since 2007, he has been at King Mongkut's Institute of Technology Ladkrabang. His research interests are in high-voltage engineering applications and sensors.

(peerawut.yu@kmitl.ac.th)

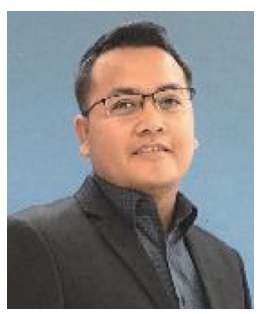

Tongpian Prombud received his B.Eng. and M.Eng. degrees from King Mongkut's Institute of Technology Ladkrabang, Thailand, in 2006 and 2012, respectively. Since 2019, he has been at Rajamangala University of Technology Krungthep. His research interests are in high-voltage engineering applications and sensors. (tongpian.p@mail.rmutk.ac.th) 